\title{
PUSAT BUDAYA PALEMBANG DI 13 ILIR, SUMATERA SELATAN
}

\author{
Febian Pratama ${ }^{1)}$ \\ 1)Program Studi S1 Arsitektur, Fakultas Teknik, Universitas Tarumanagara, \\ febian.315160004@stu.untar.ac.id
}

Masuk: 04-07-2021, revisi: 14-08-2021, diterima untuk diterbitkan: 23-10-2021

\begin{abstract}
Abstrak
Dalam persoalan ekologi melampaui, dengan melihat pada sisi ekologi budaya. Indonesia merupakan negara kepulauan yang memiliki kekayaan dan keragaman budaya nusantara yang menjadikannya sebuah daya tarik sendiri di mata dunia. Namun kondisi kebudayaan yang ada saat ini mulai ditinggalkan oleh sebagian masyarakat Indonesia yang mungkin tidak terlepas dari perkembangan zaman dan teknologi serta masuknya pengaruh budaya luar. Misalnya kota Palembang, dimana sebagai ibukota Provinsi Sumatera Selatan yang merupakan pusat pemerintahan, pusat rekreasi, pusat permukiman, pusat perdagangan dan pusat kebudayaan. Kebudayaan di wilayah tersebut menjadi peran penting didalamnya yang seharusnya tidak hilang. Sehingga pemilihan tapak berlokasi di Palembang yang berdekatan dengan Sungai Musi. Generasi muda seharusnya menjadi peran penting dalam menjaga kelestarian keanekaragaman budaya dan arsitektur lokal yang dimiliki Indonesia. Mengingat bahwa di Palembang itu sendiri belum memiliki sebuah wadah untuk menampung kebudayaan yang ada. Sehingga proyek ini dirancang berbasis pada fungsi kultural dengan membuat sebuah pusat budaya yang diyakinkan menjadi sangat penting bagi masyarakat maupun penerus bangsa agar tetap dapat melestarikan sebuah kultural yang ada di Palembang dalam konteks ekologi melampaui.
\end{abstract}

\section{Kata kunci: Generasi muda; Kebudayaan; Kultural; Palembang}

\begin{abstract}
In terms of beyond ecology, by looking at the culture ecology side. Indonesia is an archipelagic country that has the wealth and diversity of the archipelago's culture which is an attraction in itself in the eyes of the world. However, the current cultural conditions are starting to be abandoned by some Indonesian people, which may not be separated from the times and technology as well as the entry of foreign cultural influences. For example the Palembang city, which is the capital city of South Sumatra as the center of government, recreation, cultural, and trade center. Culture in the region becomes an important role in it that should not be lost. So the site is located in Palembang close to the Musi River. The younger generation must play an important role in preserving the diversity of culture and local architecture that Indonesia has. Palembang itself does not yet have a place to accommodate the existing culture. So the project is designed based on cultural functions by creating a cultural center that is believed to be very important for the community and the nation's successors in order to keep a culture that exists in Palembang based on beyond ecology.
\end{abstract}

\section{Keywords: Cultural; Culture; Palembang; Younger generation}

\section{PENDAHULUAN Latar Belakang}

Istilah ekologi pertama kali diperkenalkan oleh Ernest Haeckel, seorang ahli biologi kebangsaan Jerman. Ekologi berasal dari Bahasa Yunani yaitu Oikos yang berarti rumah dan logos yang berarti ilmu. Sehingga ekologi dapat diartikan sebagai ilmu yang mempelajari hubungan timbal balik antara mahluk hidup dengan lingkungannya. Di dalam ekologi terdapat jenis ekologi budaya yang didefinisikan sebagai studi tentang peran budaya sebagai komponen dinamis dari 
setiap ekosistem menurut antropolog Charles O. Frake (1962), seperti suku atau adat istiadat, kerajinan tangan, peninggalan sejarah, dll. Terdapat juga hubungan antara ekologi dengan pariwisata yang memiliki tanggung jawab kepada lingkungan dan masyarakat sekitar yang biasa disebut dengan ekowisata. Dari ekowisata itu terbagi menjadi beberapa jenis dan yang akan di bahas di dalamnya adalah jenis ekowisata kebudayaan dan sejarah. Palembang merupakan kota tertua yang juga merupakan ibu kota Provinsi Sumatera Selatan yang berumur setidaknya 1337 tahun jika berdasarkan prasasti kedukan bukit. Secara geografis Kota Palembang dibelah oleh Sungai Musi menjadi dua bagian yaitu seberang ulu di bagian selatan dan seberang ilir di bagian utara. Kota Palembang juga terdapat jembatan Ampera yang berdiri di atas Sungai Musi yang merupakan ikon Kota Palembang yang memberikan banyak manfaat bagi kota Palembang. Salah satunya menjadi tempat rekreasi atau pariwisata, sehingga pemerintah kota Palembang berusaha memaksimalkan potensi dari memanfaatkan Sungai Musi untuk peningkatan kesejahteraan masyarakat Kota Palembang.

Sebagai pusat pemerintahan di Provinsi Sumatera Selatan, Palembang memiliki banyak unsur kebudayaan dari rumah adat, tarian daerah, lagu daerah, pakaian adat, alat musik, dan makanan khasnya. Sayangnya kebudayaan seperti tarian adat, lagu daerah yang ada ini sudah mulai hilang atau memudar karena perkembangan jaman dan teknologi sehingga kebudayaankebudayaan asli menjadi tidak terlalu diminati lagi oleh masyarakatnya. Bila kebudayaan tersebut ditinggalkan, maka lama kelamaan kebudayaan Palembang juga akan hilang. Palembang sendiri belum memiliki wadah yang tepat untuk memusatkan kegiatan-kegiatan tersebut. Sehingga "pusat budaya" diperlukan sebagai tempat bertukar pikiran, tempat belajar dan mengenalkan kebudayaan Palembang kepada dunia.

\section{Rumusan Masalah}

Ada beberapa hal yang akan dibahas dalam makalah ini yaitu apa itu kebudayaan Palembang, apa yang dimaksud dengan pusat budaya, dan bagaimana sebuah pusat budaya dapat terbentuk dalam lingkungan masyarakat.

\section{Tujuan}

Tujuan dari proyek ini adalah untuk menjadikan sebuah wadah dari kegiatan dan kebudayaankebudayaan yang ada di Palembang untuk berkumpul, belajar, bertukar pikiran, dll. Selain itu proyek ini bertujuan menjadikan sebagai salah satu destinasi wisata berbasis kultur yang menarik untuk dikunjungi oleh wisatawan lokal, mancanegara dan masyarakat Palembang itu sendiri dengan mengenalkan kebudayaan yang ada di Palembang.

\section{KAJIAN LITERATUR}

\section{Ekologi dan Ekologi melampaui}

Ekologi adalah ilmu yang mempelajari interaksi antara organisme dengan lingkungannya. Ekologi berasal dari kata Yunani Oikos (habitat) dan Logos (ilmu) sehingga diartikan sebagai ilmu yang mempelajari baik interaksi antara makhluk hidup maupun interaksi antara makhluk hidup dan lingkungannya. Dalam ekologi, makhluk hidup dipelajari sebagai kesatuan atau sistem dengan berbagai komponen penyusunnya yaitu faktor abiotik dan biotik (Setiawan, 2021). Dalam ekologi juga terdapat ekologi budaya. Menurut Charles O. Frake mendefinisikan sebagai studi tentang peran budaya sebagai komponen dinamis dari setiap ekosistem. Salah satu bagian dari ekologi budaya yang berdampak adalah studi tentang adaptasi, bagaimana menghadapi, mempengaruhi dan dipengaruhi oleh perubahan lingkungan. Ekologi melampaui, adalah cara ekologi baru mengeksplorasi kemungkinan-kemungkinan yang selama ini mungkin belum tersklorasi atau mungkin menghasilkan penciptaan baru tentang ekologi yang dibuat oleh manusia yang kemudian menjadi sistem bagi ekosistem bumi. Jika mempelajari ekologi secara komprehensif maka diharapkan pembentukkan ekologi yang dirancang mampu 
memberikan distribusi positif terhadap ekosistem-ekosistem lainnya, sehingga mampu membuat penciptaan ekologi "baru" atau pengembangan ekologi yang sudahh ada yang diharapkan mampu mendukung ekologi yang ada.

\section{Pariwisata dan Ekologi}

Hubungan antara pariwisata degan ekologi dapat membentuk sebuah kegiatan wisata yang memiliki tanggungjawab kepada alam, lingkungan dan masyarakat sekitar atau biasa disebut dengan ekowisata. Dengan jenis-jenis kegiatan ekowisata di Indonesia terbagi menjadi 5 kategori wisata (Sugiarti, 2015), yaitu ekowisata pemandangan (meliputi objek alam seperti pantai dan air terjun; flora seperti hutan; fauna; dan perkebunan berupa perkebunan teh, kopi, sayur dan buah); ekowisata petualangan (seperti kegiatan alam bebas: mendaki gunung, lintas alam, berselancar, dan lainnya); ekowisata kebudayaan dan sejarah (yang meliputi: suku terasing atau pedalaman seperti orang rimba dan suku Dayak; kerajinan tangan baik dan ukiran; dan peninggalan sejarah seperti candi, benteng kolonial, dan lainnya); ekowisata penelitian yang meliputi pendataan spesies (pendataan kerusakan alam seperti lahan gundul dan pencemaran lingkungan serta kegiatan koservasi seperti reboisasi dan lokalisasi pencemaran); ekowisata sosial (koservasi dan Pendidikan yang meliputi pembangunan fasilitas kesehatan dan komunikasi di wilayah dekat ekowisata; reboisasi hutan gundul, pengembangan flora dan fauna yang mulai terancam kelestariannya; dan memberikan Pendidikan bagi masyarakat di sekitar kawasan wisata, seperti mengajarkan bahhasa inggris, meningkatkan minat baca, dan lainnya)

\section{Palembang}

Palembang memiliki ikonnya yaitu Sungai Musi dan jembatan Ampera. Hal ini memberikan banyak manfaat bagi kota Palembang sehingga pemerintah Palembang berusaha memaksimalkan potensi dari memanfaatkan sungai Musi untuk meningkatkan kesejahteraan masyarakat kota Palembang. Ide dasar penataan kawasan tepian Sungai Musi dilakukan dengan mempertimbangkan potensi-potensi pengembangan yang dimiliki oleh kawasan sepanjang tepian sungai dan memperhatikan pula kendala yang ada. Seperti dalam usulan rencana penataan tepian sungai musi yang merupakan pengembangan aktifitas kota di sepanjang tepian sungai dalam konsep waterfront / river side harus diekspos semaksimal mungkin untuk kepentingan publik malalui pengembangan node-node kegiatan pada beberapa lokasi strategis yang berseberangan; pembentukan pola-pola poros jalan yang mengarah ke sungai sehingga membentuk bukaan view ke air, sekaligus mengantisipasi peningkatan aksesibilitas kedua sisi berseberangan melalui angkutan air; pengembangan promenade berupa pedestrian/ jalan di tepian sungai.

Tabel 1. Node yang Dikembangkan dalam Penataan Kawasan Tepi Sungai Musi

\begin{tabular}{l|l|l}
\hline No. & \multicolumn{1}{|c}{ Lokasi Node } & Kegiatan pengisi \\
\hline 1. & $\begin{array}{l}\text { Benteng Kuto Besak, Mesjid Agung, Mesjid Lawang Kidup, } \\
\text { Kampung Kapiten, Bagus Kuning, Kelenteng 10 ulu, 16 Ilir, } \\
\text { Kampung Palembang 3/4 Ulu }\end{array}$ & $\begin{array}{l}\text { Wisata sejarah, kegiatan } \\
\text { perlombaan, acara-acara } \\
\text { nasional, taman kota }\end{array}$ \\
\hline 2. & Pelabuhan boom baru & Kegiatan Pelabuhan \\
\hline 3. & Pulau Kemarau & Wisata sejarah \\
\hline 4. & Kaki jembatan Ampera & Taman kota \\
\hline
\end{tabular}

Sumber: PERDA Kota Palembang Nomor 15 Tahun 2012, Tentang Rencana Tata Ruang Wilayah (RTRW) Kota Palembang Tahun 2012-2032, 2012

Kebudayaan Sumatera Selatan sebagian besar dipengaruhi oleh kebudayaan Melayu, Islam, dan dari kerajaan Sriwijaya. Kekayaan budaya Sumatera Selatan meliputi rumah adat, taritarian tradisional, pakaian adat, makanan khas, lagu-lagu daerah, dan alat musik daerah. 
Tabel 2. Ragam Kebudayaan yang ada di Palembang

\begin{tabular}{|c|c|c|}
\hline No. & Ragam Kebudayaan & Pengertian \\
\hline 1. & Rumah Limas & $\begin{array}{l}\text { Rumah Limas telah diakui sebagai rumah adat tradisional Sumatera } \\
\text { Selatan. Secara umum arsitektur dari Rumah Limas ini Nampak pada } \\
\text { atapnya berbentuk menyerupai limasan. Keunikan rumah Limas } \\
\text { lainnya terdapat pada bentuknya yang bertingkat-tingkat, dinding } \\
\text { berupa kayu merawan dan dibangun diatas tiaing-tiang atau cagak. }\end{array}$ \\
\hline 2. & Tari Gending Sriwijaya & $\begin{array}{l}\text { Tari yang ditampilkan secara khusus untuk menyabut tamu-tamu } \\
\text { seperti kepala negara, duta besar dan tamu-tamu agung lainnya. }\end{array}$ \\
\hline 3. & Tari Tanggai & $\begin{array}{l}\text { Tarian ini ditampilkan untuk menyabut tamu atau dalam acara } \\
\text { pernikahan. Biasanya tarian ini beranggotakan lima orang dengan } \\
\text { pakaian khas dari Palembang. }\end{array}$ \\
\hline 4. & Tari Madik (Nindai) & $\begin{array}{l}\text { Sebuah tarian adat yang digunakan saat akan memilih calon, kemudian } \\
\text { orangtua pria akan terlebih dahulu dating kerumah wanita untuk } \\
\text { melihat dan menilai (madik dan nindai). }\end{array}$ \\
\hline 5. & $\begin{array}{l}\text { Pakaian adat } \\
\text { gede dan Aesan } \\
\text { paksangko) }\end{array}$ & $\begin{array}{l}\text { "Aesan gede" melambangkan kebesaran dan "Aesan paksangko" } \\
\text { melambangkan keaggunan masyarakat Sumatera Selatan. Di dalam } \\
\text { pakaian adat tersebut terdapat unsur filosofi hidup dan keselarasan } \\
\text { yang dapat dilihat dari pemilihan warna dan corak yang menghiasi } \\
\text { pakaian tersebut. }\end{array}$ \\
\hline 6. & Kain Songket & $\begin{array}{l}\text { Kain songket merupakan salah satu peninggalan Kerajaan Sriwijaya } \\
\text { yang dikerjakan dengan menenun antara benang emas dan perak di } \\
\text { atas benang lungsing dengan warna-warna cerah yang melambangkan } \\
\text { keemasan Kerajaan Sriwijaya dan pengaruh Cina di masa lampau. }\end{array}$ \\
\hline 7. & Makanan khas & $\begin{array}{l}\text { Terdapat banyak makanan khas dari Sumatera Selatan, beberapa yang } \\
\text { paling popular adalah pempek, tempoyak, pindang, mie celor, tekwan, } \\
\text { dll. }\end{array}$ \\
\hline 8. & Lagu daerah & $\begin{array}{l}\text { Lagu - lagu daerah ini biasanya ditampilkan saat acara pernikahan, } \\
\text { pemerintahan, hingga kumpul keluarga. Beberapa lagu daerah khas } \\
\text { Palembang, seperti: Ya Saman, Cuk Mak llang, Dek Sangke, Gending } \\
\text { Sriwijaya,dll. }\end{array}$ \\
\hline 9. & Alat musik daerah & $\begin{array}{l}\text { Alat musik tradisional ini berfungsi sebagai pengiring pertunjukan seni } \\
\text { tradisional seperti tarian dan lagu daerah. Beberapa alat musik } \\
\text { tradisional Palembang: Gambus, Gendang Oku, Kenong Basemah, dll }\end{array}$ \\
\hline
\end{tabular}

Sumber: dipalembang.com, 2021

\section{Pusat Budaya}

Menurut Kamus Besar Bahasa Indonesia (KBBI), pengertian kata pusat adalah pokok pangkal atau yang jadi pumpunan dan budaya adalah hasil kegiatan dan penciptaan batin (akal budi manusia), seperti kepercayaan, kesenian, dan adat istiadat. Sehingga pusat budaya adalah suatu wadah atau tempat berlangsungnya kegiatan seperti kepercayaan, kesenian, adat istiadat yang digunakan untuk mempromosikan potensi budaya dan mengembangkan sektor pariwisata.

Pada pusat budaya terdapat beberapa kebutuhan akan fungsi yang perlu diwadahi, yaitu: ceramah, temu karya, lokakarya, publikasi, pementasan diwadahi di dalam auditorium/teater atau ruang pertemuan; Pagelaran, pameran, pekan seni diwadahi di dalam ruang pameran (exhibiton); Pengolahan dan eksperimentasi seni diwadahi di dalam studio atau ruang pertunjukan; Menjaga, merawat dan membina kesenian daerah, penggalian dan pemeliharan seni daerah diwadahi di dalam studio atau ruang studi; Mengumpulkan dan menyimpan sumber-sumber informasi, mengolah sumber informasi dan menyebarluaskan kembali ke masyrakat sebagai informasi baik / promosi diwadahi di dalam perpustakaan, ruang arsip, ruang informasi, dan pameran; Urusan tata usaha diwadahi di dalam ruang tata usaha atau administrasi. 


\section{METODE}

Dalam proses penelitian ini, yang pertama kali dilakukan adalah mencari isu yang terjadi saat ini dan berpengaruh dalm kehidupan manusia di masa yang akan datang. Kemudian ditemukan bahwa isu yang terjadi saat ini adalah semakin kurangnya kesadaran manusia terhadap kebudayaan-kebudayaan yang ada dalam daerahnya untuk kehidupan di masa depan terutama di kota-kota besar. Selanjutnya melakukan riset terhadap penyebab munculnya isu yang diangkat dan penyelesaiannya. Dalam riset ditemukan bahwa salah satu penyebab semakin kurangnya kesadaran itu adalah perkembangan jaman dan kurangnya wadah untuk menampung kebudayaan-kebudayaan yang ada, sehingga muncul peluang untuk mengajukan proyek sebuah pusat budaya dalam bentuk yang lebih menarik dan modern. Kemudian dilakukan pencarian tapak yang memiliki latar belakang atau ciri khas kawasan tertentu dan ditemukan kawasan Sungai Musi, tepatnya di kelurahan 13 llir, Palembang dengan latar belakang kawasan bersejarah yang memiliki potensi-potensi yang dapat mendukung pengembangan proyek, sehingga dapat menambah kekayaan objek dan atraksi budaya lokal yang khas.

Tabel 3. Objek Atraksi Wisata dan Budaya Kawasan Sungai Musi

\begin{tabular}{l|l|l}
\hline No. & \multicolumn{1}{|c|}{ Nama Objek } & \multicolumn{1}{c}{ Jenis } \\
\hline 1. & Jembatan Ampera & Sejarah \\
\hline 2. & Benteng Kuto Besak & Sejarah \\
\hline 3. & Monumen Monpera & Sejarah \\
\hline 4. & Museum Sultan Mahmud Badaruddin II & Budaya \\
\hline 5. & Kampung Arab & Budaya \\
\hline 6. & Kampung Kapitan & Budaya \\
\hline 7. & Pulau Kemaro & Religi \\
\hline 8. & Masjid Agung & Religi \\
\hline 9. & Pasar 16 ilir & Belanja \\
\hline
\end{tabular}

Sumber: Penulis, 2021

Setelah melakukan pencarian tapak, kemudian melakukan proses merancang dengan metode regionalisme dan kontemporer sesuai dengan fungsi bangunan sebagai pusat budaya. Sehingga diharapkan tidak meninggalkan unsur budaya yang ada dan dirancang dalam bentuk yang lebih modern dan menarik.

\section{DISKUSI DAN HASIL}

\section{Lokasi Tapak}

Lokasi tapak berada di jalan Ali Gatmir, 13 Ilir, llir Timur 1, Palembang, Sumatera Selatan dengan data tapak seperti luas sebesar $10.000 \mathrm{~m}^{2}$, KDB 80\%, KDH >20\%, KLB 3, GSB $4.5 \mathrm{~m}$, GSS 30m, Zona pariwisata.

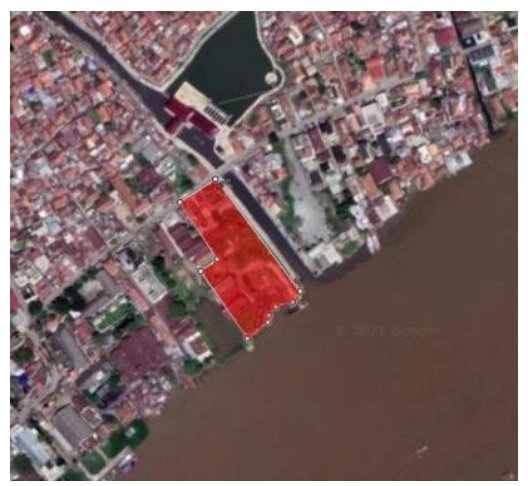

Gambar 1. Peta Lokasi Tapak

Sumber: Google maps, 2021 


\section{Aktivitas dan Program}

Berdasarkan isu yang di ambil dan dilihat dari letak maupun kondisi lingkungan sekitar tapak ini memiliki latar belakang sebagai sebuah kawasan pariwisata yang terdiri dari wisata sejarah. Maka dapat diusulkan program yang dapat dibentuk adalah sebuah program yang berkaitan dengan sebuah pusat budaya, yang terdiri dari sebuah area pentas seni, area pameran, dan area penunjangnya seperti area belajar (perpustakaan, seminar, workshop), kantin, pusat oleh-oleh, area berkumpul, dll. Program-program tersebut diusulkan dengan tujuan agar pengunjung yang datang tidak hanya sekedar melihat lihat, namun juga mereka dapat bekumpul dan juga belajar mengenai sejarah yang ada di Palembang. Kemudian dari program-program tersebut, dirancang pembagian area menurut filosofi dari rumah limas Palembang.

Tabel 4. Aktivitas dan Program

\begin{tabular}{|c|c|c|c|}
\hline No. & Area & Pengertian & Program \\
\hline \multirow[t]{4}{*}{1.} & \multirow{4}{*}{$\begin{array}{l}\text { Lantai } 1 \text { (Pagar } \\
\text { Tenggalung) }\end{array}$} & \multirow{4}{*}{$\begin{array}{l}\text { Merupakan ruangan yang difungsikan untuk } \\
\text { menerima tamu }\end{array}$} & Lobby \\
\hline & & & Kafetaria \\
\hline & & & Pameran temporer \\
\hline & & & R. pengelola \\
\hline \multirow[t]{5}{*}{2.} & \multirow[t]{5}{*}{ Lantai 2 (Jogan) } & \multirow{5}{*}{$\begin{array}{l}\text { Merupakan ruangan dengan fungsi sebagai } \\
\text { tempat berkumpul }\end{array}$} & R. terbuka hijau \\
\hline & & & amphiteater \\
\hline & & & Retail \\
\hline & & & Toko Suvenir \\
\hline & & & Perpustakaan \\
\hline \multirow[t]{3}{*}{3.} & \multirow{3}{*}{$\begin{array}{l}\text { Lantai } 3 \\
\text { (Kekijing) }\end{array}$} & \multirow{3}{*}{$\begin{array}{l}\text { Merupakan ruang yang lebih memiliki } \\
\text { privasi di banding ruangan sebelumnya. }\end{array}$} & R. komunal \\
\hline & & & Perpustakaan \\
\hline & & & Pameran temporer \\
\hline \multirow[t]{3}{*}{4.} & \multirow[t]{3}{*}{ Lantai 4} & \multirow{3}{*}{$\begin{array}{l}\text { Merupakan ruang khusus bagi orang yang } \\
\text { dihormati, seperti tamu undangan }\end{array}$} & R. seminar \\
\hline & & & R. Workshop \\
\hline & & & Pameran permanen \\
\hline
\end{tabular}

Sumber: Indonesia.go.id, 2019

\section{Gubahan Massa}

Bentuk awal gubahan mengikuti bentuk dari tapaknya, lalu volume massa ditambahkan.

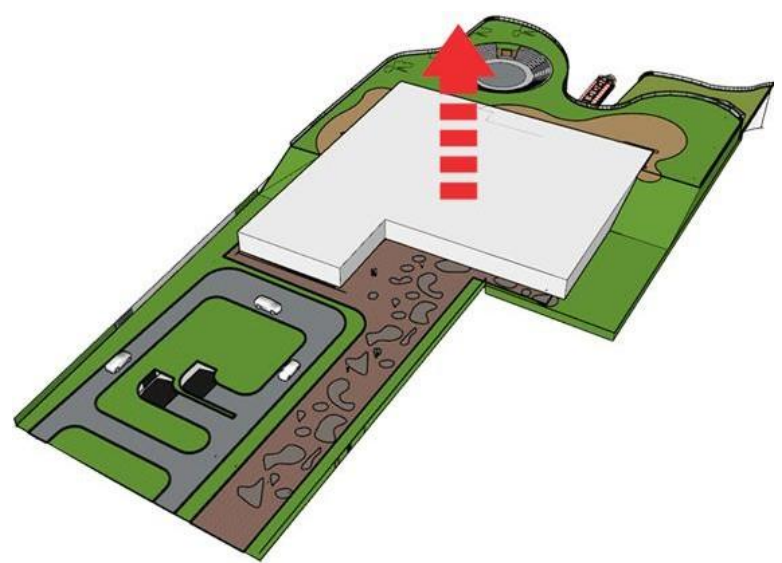

Gambar 2. Gubahan Massa ke-1 Sumber: Penulis, 2021 
Kemudian terbentuk sebuah massa baru dengan volume yang lebih besar.

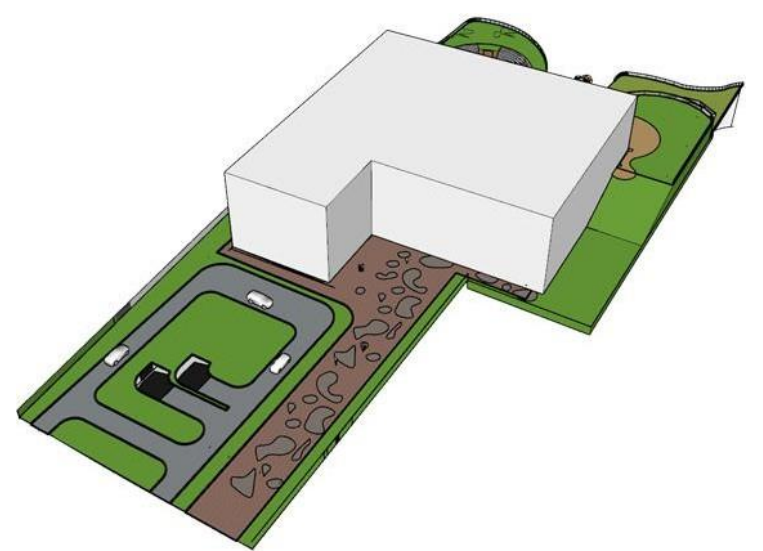

Gambar 3. Gubahan Massa ke-2 Sumber: Penulis, 2021

Lalu massa dibelah menjadi 2 dari arah darat ke sungai, maupun sebaliknya sebagai akses pencapaian ke massa.

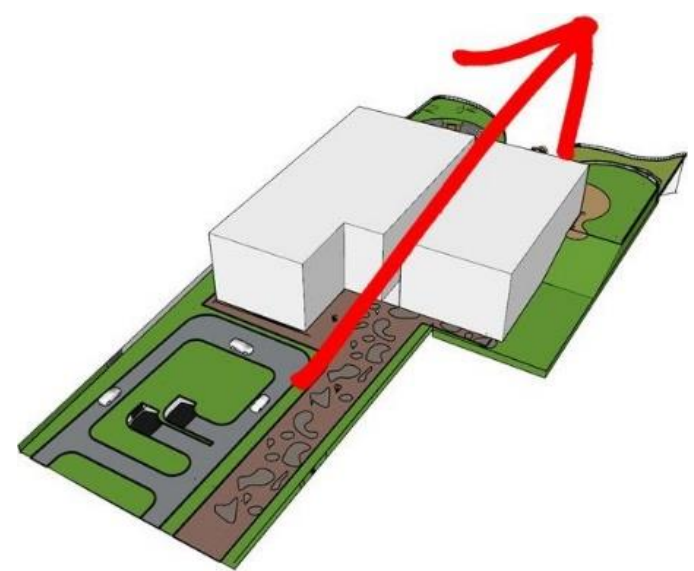

Gambar 4. Gubahan Massa ke-3 Sumber: Penulis, 2021

Kemudian dinding di sisi depan massa bagian kanan dimiringkan untuk memberikan kesan mengajak masuk ke dalam bangunan.

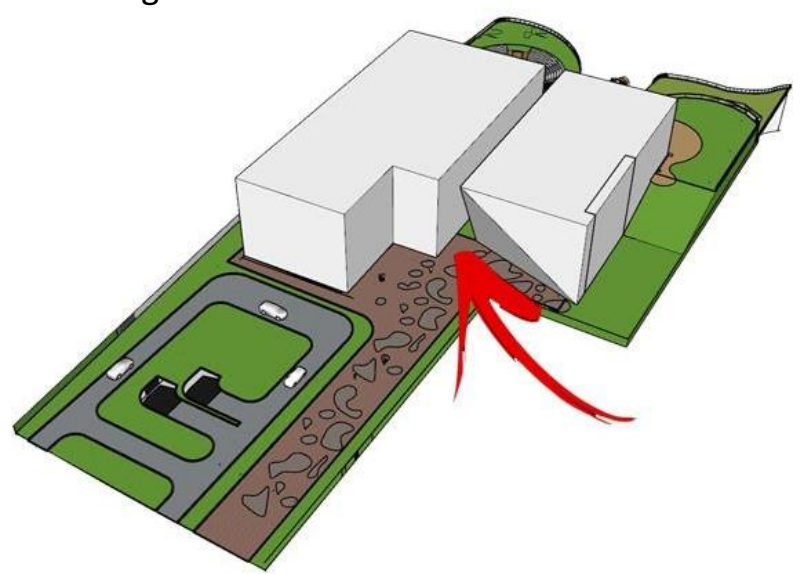

Gambar 5. Gubahan Massa ke-4 Sumber: Penulis, 2021 
Lalu diberikan beberapa bukaan di bagian-bagian tertentu agar massa mendapatkan pencahayaan dan pengudaraan alami dengan baik. Bukaan hidup difokuskan pada massa di bagian sebelah kiri.

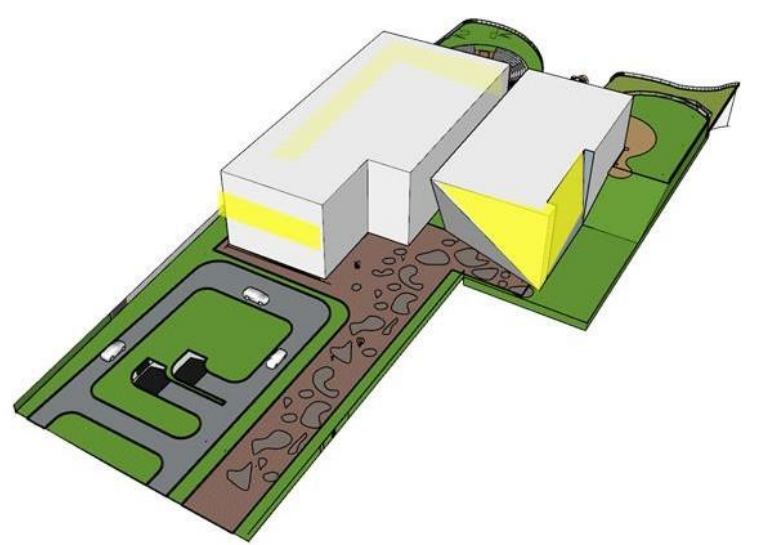

Gambar 6. Gubahan Massa ke-5 Sumber: Penulis, 2021

Bentuk akhir bagian massa di sebelah kiri sedikit diturunkan agar volume di sisi kanan dan kiri seimbang.

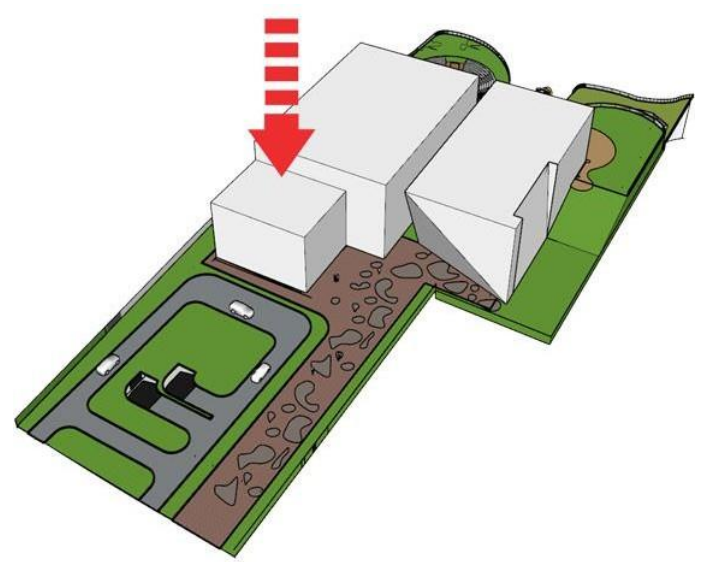

Gambar 7. Gubahan Massa ke-6 Sumber: Penulis, 2021

Akhirnya terdapat dua massa, dimana fungsi massa itupun berbeda. Massa di sebelah kiri difokuskan sebagai fungsi penunjang dari pusat budaya, seperti seminar, workshop, perpustakaan, ruang komunal, dll. Dan massa di sebelah kanan difokuskan sebagai fungsi utamanya yaitu pameran.

\section{Denah}

Lantai basement digunakan sebagai area parkir serta ruang-ruang servis yang meliputi ruang genset, ruang STP, WTP, ruang pompa, dan panel induk. Selain itu, diberikan beberapa fasilitas penunjang berupa musholla dan ruang tunggu supir. 


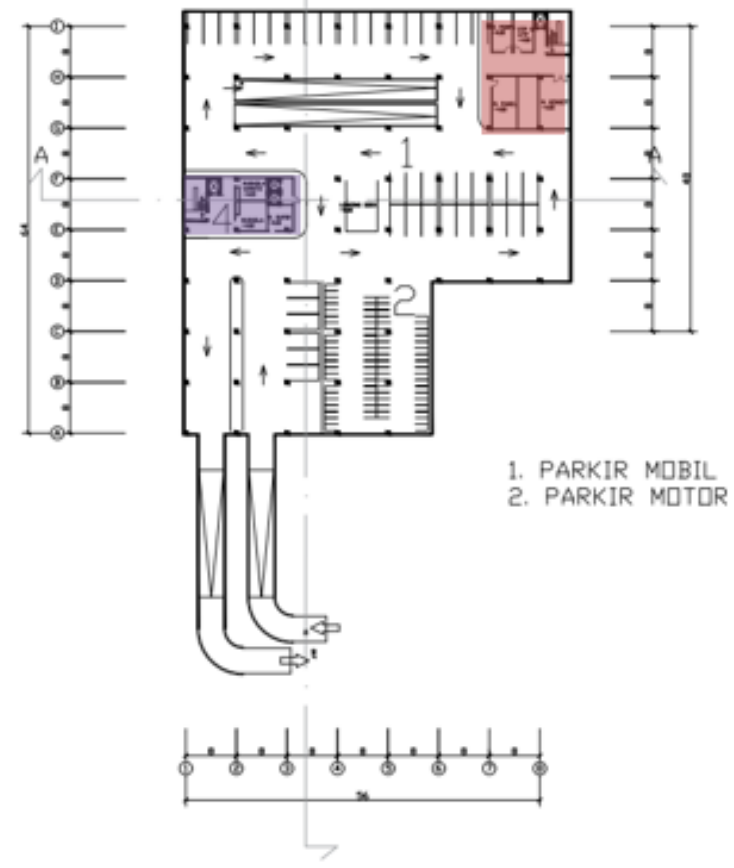

Gambar 8. Denah Lantai Basement Sumber: Penulis, 2021

Lantai satu atau lantai dasar bangunan terdapat fungsi penerima meliputi area lobby, area parkir. Terdapat juga fungsi servis meliputi ruang keamanan atau CCTV, ruang pengelola dan kantin. Karena ada permainan landscape sehingga membuat beberapa bagian menjadi bagian semibasement. Di massa bagian kanan terdapat fungsi sebagai ruang pameran temporer.

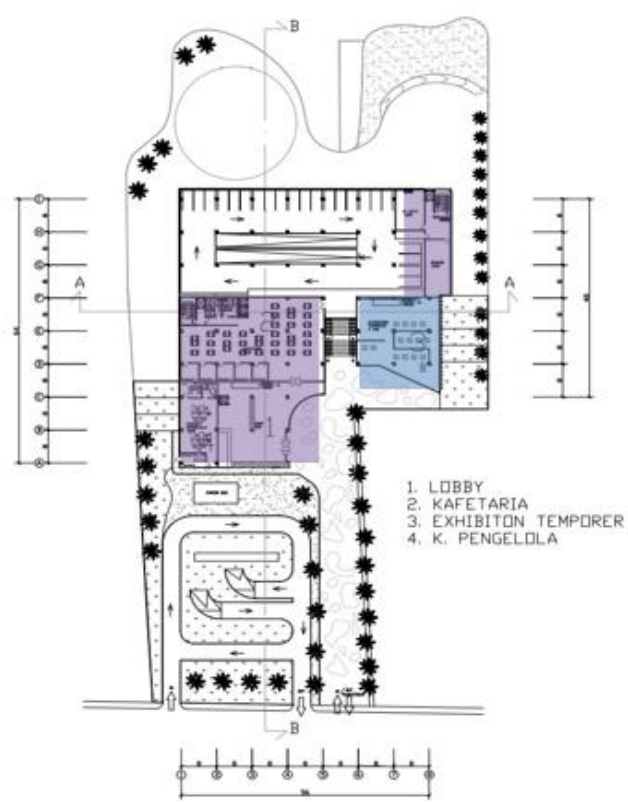

Gambar 9. Denah Lantai Dasar

Sumber: Penulis, 2021

Lantai dua bangunan yang difokuskan sebagai tempat berkumpul ini dibagi menjadi dua massa yang dipisahkan dengan sebuah selasar ditengah bangunan. Pada massa di sebelah kiri terdapat area komersil, seperti retail, dan toko suvenir, terdapat juga perpustakaan sebagai 
tempat belajar. Lalu di massa sebalah kanan tedapat lobby utama sebagai bagian dari fungsi pameran. Kemudian pada bagian landscape belakang bangunan terdapat amphiteather sebagai tempat seni pertunjukan tari khas Palembang, promenade sebagai tempat berkumpul, dan dermaga sebagai pencapaian melalui akses sungai.

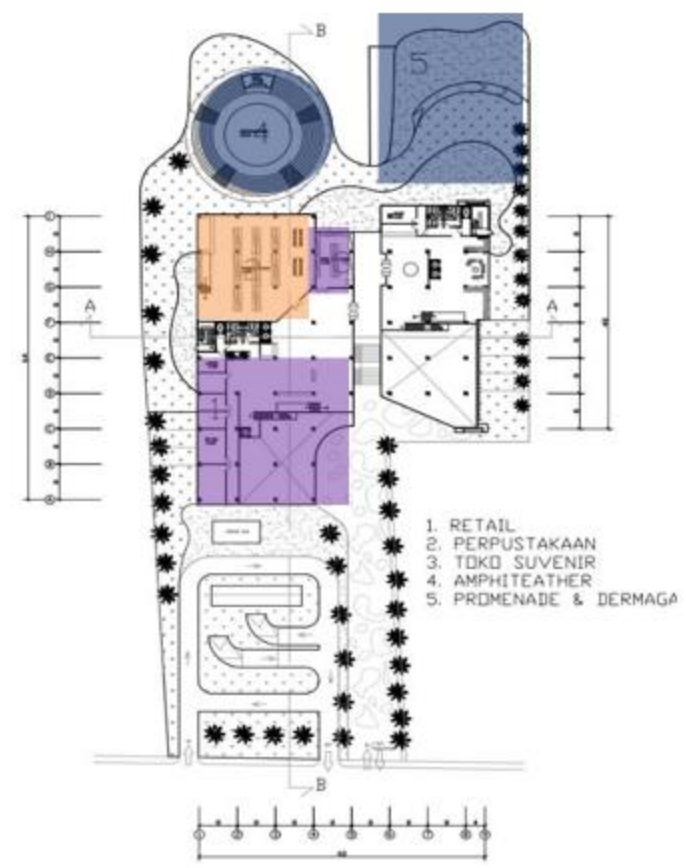

Gambar 10. Denah Lantai 2

Sumber: Penulis, 2021

Pada lantai tiga yang memiliki privasi lebih dibandingkan lantai dua ini dibagi menjadi dua area, yaitu area berkumpul / belajar, dan area pameran. Area berkumpul / belajar berisi perpustakaan yang berhubungan dengan perpustakaan di lantai dua, dan ruang komunal.
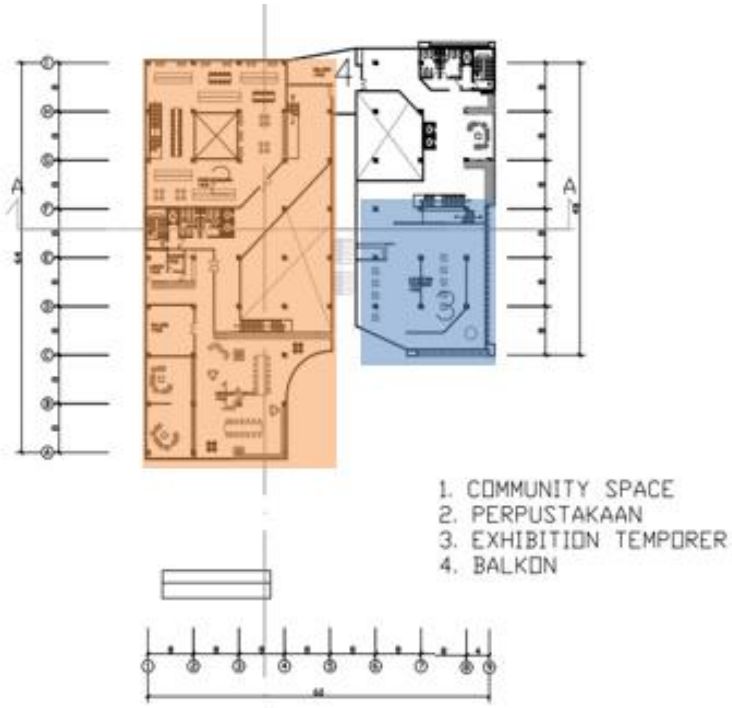

Gambar 11. Denah Lantai 3

Sumber: Penulis, 2021

Lantai empat digunakan sebagai area yang bersifat khusus bagi tamu undangan atau pengunjung yang sudah membeli tiket untuk belajar di massa bagian kiri dan area pameran untuk massa di sebelah kanan. Area belajar meliputi ruang seminar dan ruang workshop. 
Sedangkan untuk area pameran merupakan area pameran permanen, dimana pameran yang digunakan adalah pameran yang menggabungkan dengan sebuah pameran berbasis digital.

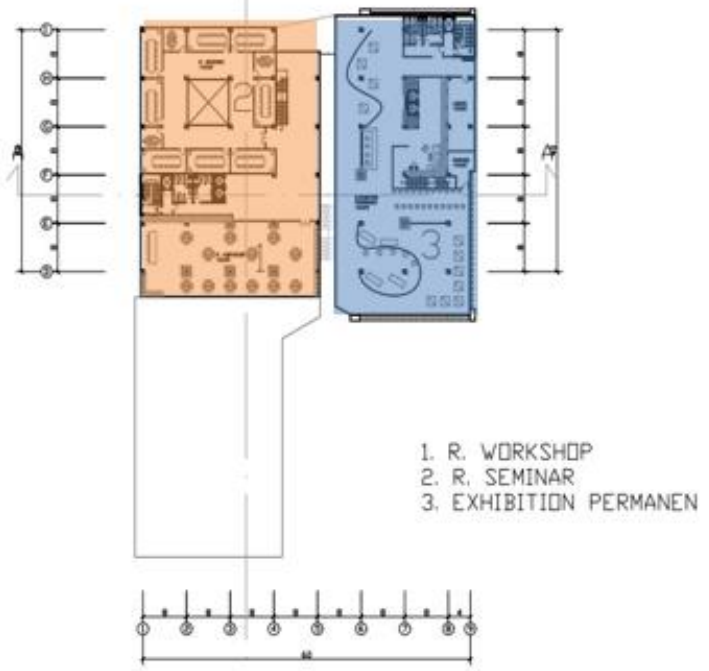

Gambar 12. Denah Lantai 4

Sumber: Penulis, 2021

Pada bagian atap bangunan digunakan untuk meletakkan reservoir atas, karena sistem air yang digunakan adalah sistem downfeed.

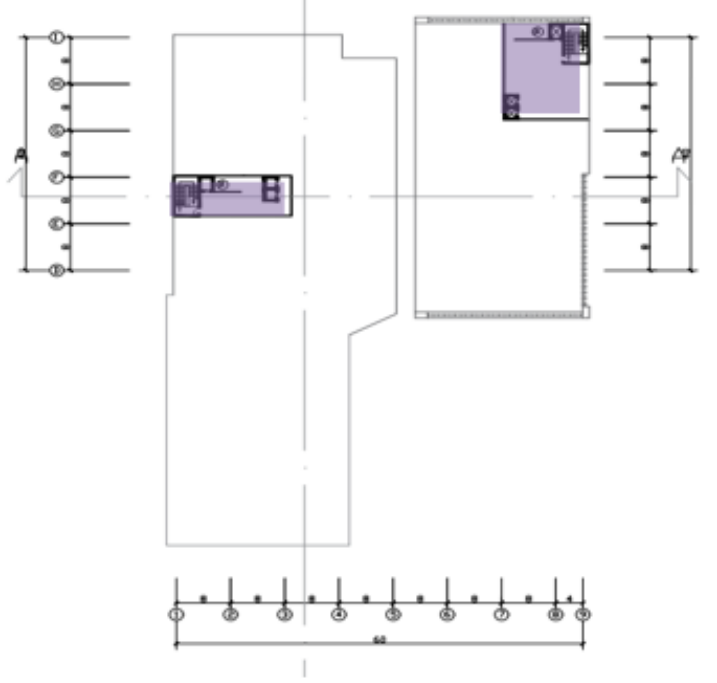

Gambar 13. Denah Atap

Sumber: Penulis, 2021

\section{Penerapan Ide Desain pada Bangunan}

Bangunan dirancang dengan fungsi sebagai pusat budaya yang berkaitan dengan ekologi, sehingga bangunan dirancang dengan beberapa ide desain di dalamnya. Ide desain yang pertama adalah membangun bangunan tiap lantainya berdasarkan filosofi Rumah Limas yang merupakan rumah adat dari Palembang. Kedua adalah merancang bangunan dengan banyak bukaan sehingga mengurangi pemakaian $A C$ dan mendapatkan pencahayaan dan pengudaraan alami yang adpat masuk ke dalam bangunan. Namun bukaan hidup tersebut difokuskan ke bagian massa yang memiliki fungsi penunjang. Karena untuk massa yang memiliki fungsi pameran memerlukan bantuan cahaya buatan yang lebih baik untuk menarik perhatian pengunjung. Ide ketiga diambil dari bentuk panel-panel yang ada di luar bangunan, dimana panel tersebut diambil dari bentuk atau corak dari kain songket yang merupakan kain khas dari 
Palembang. Panel tersebut akan diletakkan di setiap sisi bangunan, sehingga dapat terlihat di semua bagian oleh pengunjung. Panel itu juga dapat menjadi sebuah ikon yang baik untuk menggambarkan bagian dari sebuah pusat budaya. Keempat adalah penggunaan dermaga sebagai pencapaian lain menuju tapak. Dermaga itu sendiri dapat digunakan sebagai alat transportasi penyebrangan ke tempat-tempat penunjang bersejarah yang ada di sekitar Sungai Musi, seperti: Benteng Kuto Besak, Monpera, Kampung Kapitan, maupun menyebrang ke Pulau Kemarau. Penggunaan dermaga ini juga dapat membantu program pemerintah untuk mengajak penungjung mengelilingi Sungai Musi dengan kapal wisata. Keenam adalah pembuatan amphiteater di bagian luar bangunan atau di area hijau bangunan. Amphiteater tersebut akan digunakan sebagai panggung pertunjukan seni khas Palembang, seperti tarian, acara musik, dan seni pertunjukan lainnya. Selain itu amphteater ini juga dapat menjadi sebuah tempat bekumpul bagi pengunjung yang ada.

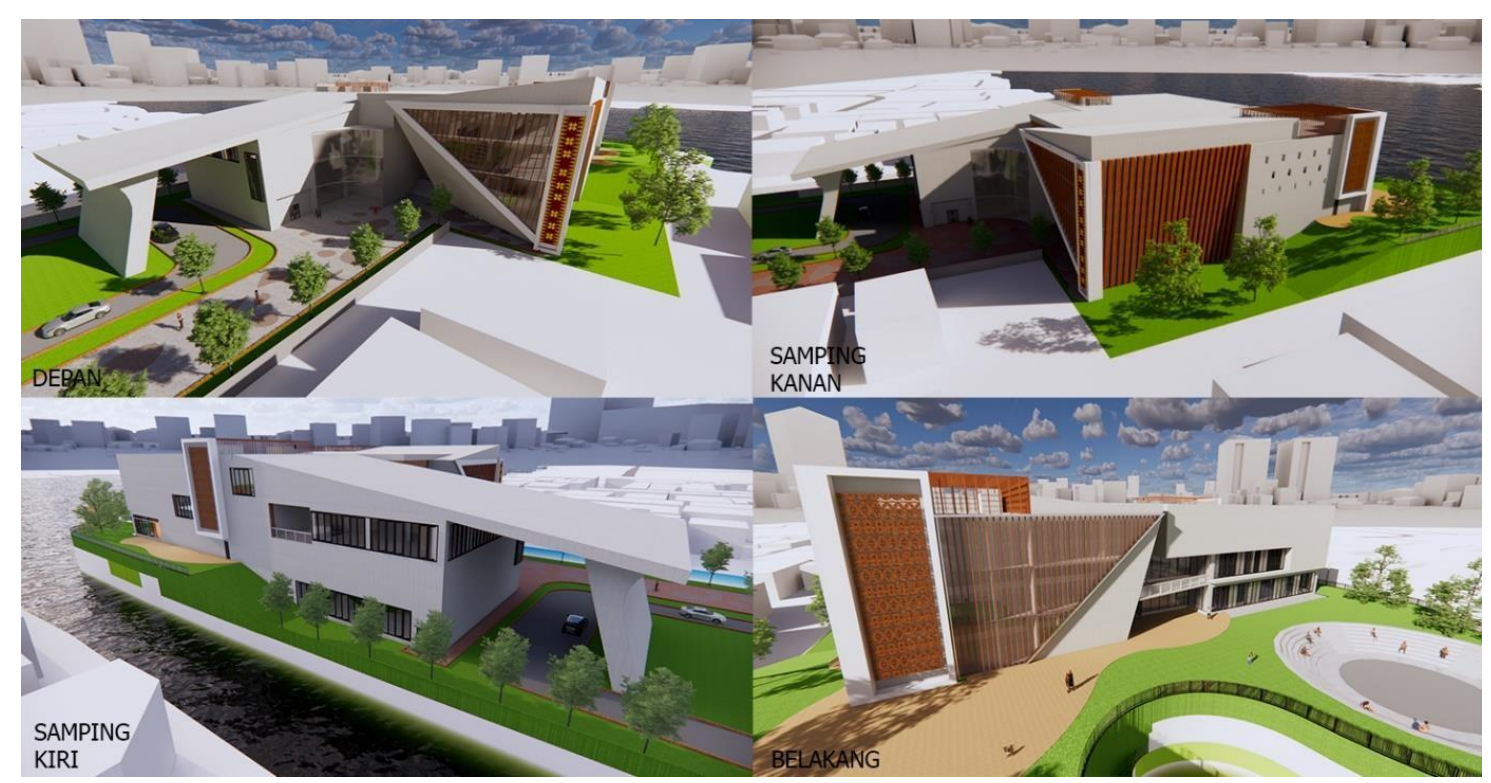

Gambar 14. Perspektif dan Letak Panel pada Bangunan

Sumber: Penulis, 2021
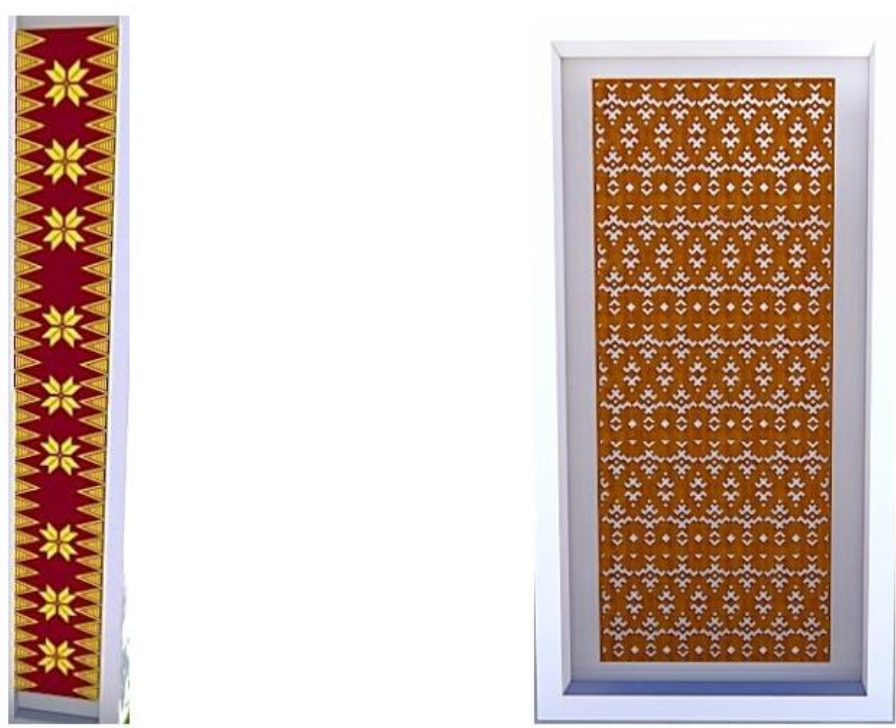

Gambar 15. Detail panel depan dan samping

Sumber: Penulis, 2021 


\section{KESIMPULAN DAN SARAN}

Pusat Budaya Palembang di 13 llir ini menjadi sebuah bagian dari peran untuk menjawab bagaimana peran arsitektur dalam pariwisata yang dapat bertanggung jawab terhadap ekologi kebudayaan. Dengan membuat sebuah bangunan yang menarik untuk sebuah pariwisata berbasis dengan kebudayaan yang terletak di Jl. Ali Gatmir, 13 llir, llir Timur 1, Palembang, Sumatera Selatan. Dimana proyek ini difokuskan sebagai tempat wisata berbasis sebuah kebudayaan yang ada di Palembang. Selain merupakan tempat wisata, proyek ini juga dimaksudkan untuk memberikan pengajaran / edukasi kepada pengunjungnya. Fungsi pengajaran / edukasi itu sendiri terdapat dalam bentuk pameran, seminar dan workshop dalam proyek ini. Mengajarkan kepada pengunjung begitu pentingnya bagian kebudayaan dalam sebuah daerah yang ada di Indonesia ini dan dalam kasus ini Palembang. Sehingga dapat menghasilkan generasi yang dapat beradaptasi dengan baik dengan perkembangan zaman ini

Karena pengaruh perkembangan jaman, menjadikan proyek ini menggabungkan metode kontemporer dalam pembentukan eksterior bangunannya sehingga tampak lebih menarik untuk sebuah pusat budaya dan regionalisme, dengan perpaduan dengan filosofi dari arsitektur lokal sehingga tidak menghilangkan unsur lokal yang ada. Sistem program dalam proyek ini dibentuk dalam bentuk yang lebih inovatif dan modern. Sistem ini dapat dilihat dalam bentuk pameran utamanya yang menggunakan campuran dengan sistem digital yang dikemas menjadi lebih menarik dan modern. Sehingga memudahkan pemahaman dan cocok bagi pengunjungnya. Proyek ini diharapkan dapat membantu Palembang untuk melestarikan kebudayaannya dan juga memajukan pariwisata di Palembang itu sendiri.

\section{REFERENSI}

Frake, C. O. (1962). Cultural Ecology and Ethnography. American Anthropologist, 53 - 59.

Jormaka, K., Schurer, O., Kuhlmann, D. (2008). Basics Design Methods. Boston: Basel Birkhauser.

Kaplan, D., Manners, R. A. (2003). Teori Budaya. Pustaka Pelajar (edisi terjemahan), cetakan III. Mulya, Q. P., Yudana, G. (2018). Analisis Pengembangan Potensi Kawasan Wisata Sungail Musi Sebagai Tujuan Wisata di Kota Palembang. Pariwisata dan Budaya, Vol 19, Nomor 2, 43 - 52. Peraturan Daerah. (2012). Rencana Tata Ruang Wilayah (RTRW) Kota Palembang Tahun 20122032. Palembang: PERDA

Poerwanto, H. (2010). Kebudayaan dan Lingkungan : dalam Perspektif Antropologi. Sleman: Jakarta Pustaka Pelajar.

Schirmbeck, E. (1993). Gagasan, Bentuk Dan Arsitektur : Prinsip-Prinsip Perancangan Dalam Arsitektur Kontemporer. Bandung: Intermatra.

Smith, S. (2005). Beyond Green : Toward a Sustainable Art. Chicago: Smart Museum of Art.

Utina, R. (2015). Ekologi dan Lingkungan Hidup. Gorontalo: UNG Press .

Administrator, (2019), Filosofi Dibalik Uniknya Rumah Limas Sumatera Selatan, indonesia.go.id: https://indonesia.go.id/ragam/budaya/kebudayaan/filosofi-dibalikuniknya-rumah-limas-sumatera-selatan

Palembang, (2021), 11 Kesenian Khas Palembang dan Sumatera Selatan, diunduh 22 Januari 2021, dipalembang.com: https://dipalembang.com/11-kesenian-khas-palembang-dansumatera-selatan/

Setiawan, P., (2021), Pengertian Ekologi dan Menurut Para Ahli, diunduh 17 Juni 2021, www.gurupendidikan.co.id: https://www.gurupendidikan.co.id/pengertian-ekologi/ 
